\title{
Espaços de produção e comercialização da agricultura familiar: as cooperativas descentralizadas do Sul Catarinense*
}

\author{
Spaces of production and marketing of family farming: the decentralized \\ cooperatives South Santa Catarina
}

\section{Des espaces de production et de commercialisation de l'agriculture familiale: les coopératives décentralisées Sud Santa Catarina}

\author{
Espacios de producción y comercialización de la agricultura familiar: las cooperativas \\ descentralizadas del Sur de Santa Catarina
}

\author{
Dimas de Oliveira Estevam** \\ (doe@unesc.net) \\ Giovana Ilka Jacinto Salvaro** \\ (giovanasalvaro@unesc.net) \\ Carla Spillere Busarello** \\ (carlaspillere@gmail.com)
}

Recebido em 17/03/2015; revisado e aprovado em 24/07/2015; aceito em 31/07/2015

DOI: http:/ / dx.doi.org/10.1590/151870122015205

\begin{abstract}
Resumo: O artigo apresenta uma discussão sobre os espaços de produção e comercialização de agricultores familiares, por meio de cooperativas rurais descentralizadas. Como procedimentos metodológicos, foram utilizadas fontes bibliográficas documentais e de campo. Além da pesquisa documental, foi realizada a de campo, em que foram entrevistados cooperados de seis cooperativas. Dentre os resultados obtidos, constatou-se que a comercialização é realizada em feiras e Programas Institucionais.
\end{abstract}

Palavras-chave: Cooperativismo. Agricultura. Mercados.

Abstract: The article presents a discussion of the areas of production and marketing of family farmers by means of decentralized rural cooperatives. The methodological procedures bibliographical, documentary and field sources were used. Besides the documentary research was carried out in the field, there were interviewed cooperative members from six cooperatives. Among the results, it was found that the marketing is performed in fairs and Institutional Programs.

Key words: Cooperative. Agriculture. Markets.

Résumé: L'article présente une analyse des zones de production et de commercialisation des agriculteurs famille par le biais de coopératives rurales décentralisées. Les procédures méthodologiques bibliographiques, sources documentaires et sur le terrain ont été utilisés. Outre la recherche documentaire a été effectuée dans le domaine, qui ont été interviewés six membres de coopératives. Parmi les résultats, il a été constaté que la commercialisation est effectuée à des foires et des programmes institutionnels.

Mots-clés: Coopération. L'agriculture. Les marchés.

Resumen: El artículo presenta un análisis de las áreas de producción y comercialización de los agricultores/familia por medio de la cooperativas rurales descentralizadas. Los procedimientos metodológicos bibliográficas, se utilizaron fuentes documentales y de campo. Además de la investigación documental se llevó a cabo en el campo, que fueron entrevistados / las cooperativas/las seis cooperativas. Entre los resultados, se encontró que la comercialización se realiza en las ferias y Programas Institucionales.

Palabras clave: Cooperativas. La agricultura. Los mercados.

\section{Introdução}

Este artigo é parte integrante de estudos realizados pelo Grupo de Pesquisa e Extensão em Desenvolvimento Socioeconômico, Agricultura Familiar e Educação do Campo (GIDAFEC/UNESC/CNPq). O GP desenvolve atividades de pesquisa e extensão sobre temáticas da agricultura familiar, organizações coletivas, redes e cadeias produtivas, consumo consciente, entre outros temas.

Os estudos sobre os processos de inserção de produtos da agricultura familiar no mercado têm despertado o interesse de

\footnotetext{
* Uma versão preliminar do artigo foi apresentada no IX Congresso ALASRU - México, 2014. Os resultados apresentados neste artigo integram uma pesquisa que tem apoio financeiro do Edital n 15/2013 PIBIC/CNPq/UNESC. ** Universidade do Extremo Sul Catarinense (UNESC), Criciúma, Santa Catarina, Brasil.
} 
muitos pesquisadores nos últimos anos. As pesquisas sobre a construção de mercados e a inserção dos produtores em cadeias mercantis estão entre as mais inovadoras, por isso têm motivado outras pesquisas. Ressalta-se que essas discussões não estão retomando o debate sobre o desenvolvimento do capitalismo na agricultura com o aparecimento de formas de inserção mercantil (SCHNEIDER, 2013).

As pesquisas atuais sobre os mercados evidenciam que há um processo em formação, em que se destaca que os mercados não são apenas espaços de interação entre demanda e oferta, restritos às leis econômicas de formação da riqueza, sua alocação e distribuição nas sociedades. Os mercados passam a ser percebidos e entendidos como espaços de interação social, formados por meio de sinais e relações que não são apenas materiais e tangíveis, mas fundamentalmente ativados mediante interações sociais, culturais e cognitivas (SCHNEIDER, 2013). Nesse sentido, o presente artigo tem como objetivo analisar os espaços de produção e comercialização de produtos de cooperativas rurais descentralizadas da Região Sul do estado de Santa Catarina.

No que compreende os procedimentos metodológicos, a pesquisa serviu-se de fonte bibliográfica documental e de campo. A documental foi realizada em arquivos das próprias cooperativas. Na de campo, optou-se pelo estudo de algumas cooperativas da região. A amostra foi definida por acessibilidade (GIL, 2010) e constituída por dezoito cooperados de cooperativas descentralizadas da região Sul de Santa Catarina. O instrumento de coleta de dados foi um questionário constituído por questões abertas e fechadas.

No processo de análise das informações, foram aliados procedimentos quantitativos e qualitativos pela estatística descritiva e análise de conteúdo. Segundo Richardson (1999), como o próprio nome indica, o método quantitativo se caracteriza pelo emprego da quantificação em processos de coleta de análise de informações. Quanto à análise de conteúdo, "entre as diversas técnicas [...] a mais antiga e a mais utilizada é a análise por categoria", [baseada] "na decodificação de um texto e, diversos elementos, os quais são classificados e formam agrupamentos analógicos" (RICHARDSON, 1999, p. 243).
O artigo está organizado em três tópicos: o primeiro trata da introdução; o segundo retoma e apresenta os espaços de produção/ comercialização de produtos da agricultura familiar; o terceiro apresenta a análise das informações obtidas nas pesquisas documental e de campo.

\section{As transformações recentes da agricultura familiar}

No Brasil, no início da década de 1960, a agricultura passou por um intenso processo de modernização, por meio da introdução de novas tecnologias, máquinas agrícolas que visavam a aumentar intensivamente a produtividade. Tal processo ficou conhecido como "revolução verde", por alavancar extraordinariamente os procedimentos produtivos agroindustriais, transformar atividades rurais em industriais, sem levar em consideração as questões ambientais, transformando rapidamente os recursos naturais em capital (MOREIRA, 1999; GOODMAN; SORJ; WILKINSON, 1990).

As consequências advindas da "revolução verde" são descritas por Palmeira (1989) como a grande concentração de terras nas mãos de poucos proprietários; a distribuição desigual da riqueza; o aumento do êxodo rural; e, ainda, o aumento da exploração de trabalho sobre as propriedades menores. Todos esses fatores contribuíram para a intensificação da desigualdade no campo, onde os grandes produtores rurais acumularam cada vez mais riqueza e os pequenos agricultores ficaram mais empobrecidos.

A partir da década de 1980, com o processo de redemocratização do país, houve a possibilidade de reorganização dos movimentos sociais e a categoria "agricultura familiar" passou a ser reconhecida pelo Estado. Com isso, os agricultores começaram a ter acesso a políticas públicas, assim como outras visões acerca da agricultura familiar e do ambiente rural (DENARDI, 2001). As políticas públicas para o meio rural trouxeram não somente o fortalecimento da agricultura familiar, mas também um desenvolvimento agrário que visa ao crescimento do ambiente rural como um todo, analisando os agentes envolvidos por diversos campos do conhecimento.

No que diz respeito ao processo de modernização do campo brasileiro e suas 
transformações para a agricultura familiar, Wanderley (2009, p. 185) enfatiza que não ocorreu a decomposição esperada do campesinato e que a agricultura familiar, enquanto forma social de produção, "ocupa um lugar importante no cenário atual da economia e da sociedade brasileiras". No entanto, entre o que fica e o que continua, Wanderley (2009) faz algumas ponderações: I) é falsa a suposição de que os camponeses não estariam interessados em produzir além de suas necessidades, pois os agricultores familiares " podem demonstrar uma importante capacidade de investimento, tanto maior quanto são efetivamente integrados aos mercados modernos" (WANDERLEY, 2009 , p. 192); II) mudança no princípio do rendimento indivisível, pois "ao se integrar ao mercado, nas condições modernas de produção, a unidade familiar introduz, em seu funcionamento, a necessidade de pagamentos diferenciados" (WANDERLEY, 2009, p. 192); III) em relação ao tempo, "enquanto o camponês tradicional ressaltava o "passado e suas tradições", a agricultura moderna, ao introduzir a noção de progresso, transfere o primado ao futuro" (WANDERLEY, 2009, p. 192); IV) a pluriatividade das famílias rurais, entendida como "uma estratégia da família, a fim de, diversificando suas atividades, fora do estabelecimento, assegurar a reprodução deste e sua permanência como ponto de referência central e de convergência para todos os membros da família" (WANDERLEY, 2009, p. 193).

Ainda, com base na autora acima, o aprendizado que pode ser obtido por meio desse processo: I) no Brasil, a agricultura familiar é relevante do ponto de vista econômico e social; II) em função do processo de modernização da agricultura que, via de regra, significa a ampliação das relações capitalistas na agricultura, esses agricultores "metamorfosearam-se" por meio da crescente "mercantilização"; III) permaneceu o trabalho familiar, contudo sua reprodução social passa a ser influenciada pela sua relação (cada vez maior) com os mercados; IV) assim sendo, o novo desafio passa a ser compreender a "morfologia" dos mercados da agricultura familiar (WANDERLEY, 2009).

Dessa maneira, a agricultura familiar está integrada ao mercado, mas não perdeu sua característica de trabalho familiar, sendo importante do ponto de vista social e econômico. No próximo tópico, discutir-se-á o modelo de cooperativismo rural descentralizado em Santa Catarina, como uma estratégia de organização dos agricultores familiares, a fim de enfrentarem os desafios atuais.

\subsection{As cooperativas descentralizadas de Santa Catarina}

Em Santa Catarina, com o objetivo de amenizar os riscos e acessar o mercado formalmente, agricultores familiares têm buscado redes de cooperação, especialmente as organizadas sob a forma de cooperativas descentralizadas. Embora essas redes de cooperação compreendam outras formas de organização (condomínios, associações e cooperativas por produto), as cooperativas descentralizadas se constituem na mais recente forma de inovação organizativa da agricultura familiar (MIOR et al., 2014).

As cooperativas descentralizadas, para os autores supracitados, são formas de organização que abrigam diversos empreendimentos e diversas atividades da agricultura familiar, constituída por uma sede e por unidades de produção e/ou filiais da cooperativa de produção agroindustrial, localizadas nas propriedades ou nas comunidades rurais dos/as associados/as. Desse modo, são descentralizadas da sede da cooperativa, e a formalização de seus empreendimentos é realizada por meio de um contrato de comodato, "cessão e uso", com a cooperativa. Para fins de legalização, as unidades são repassadas à cooperativa por meio desse contrato de comodato (por isso, elas são denominadas "descentralizadas"). As unidades descentralizadas são empreendimentos formais, filiados a uma cooperativa, cujo CNPJ utilizam (ESTEVAM et al., 2014; MIOR et al., 2014).

Essa forma de organização cooperativa, segundo Estevam et al. (2011), tem contribuído na superação de importantes gargalos na comercialização de produtos dos agricultores familiares, particularmente aos relacionados às legislações fiscais e sanitárias. Além disso, tem viabilizado as escalas mínimas de produção e logística. As cooperativas descentralizadas podem ser vistas como um mecanismo para viabilizar a entrada autônoma dos agricultores familiares no mercado. $\mathrm{O}$ acesso 
pode ocorrer de forma mais direta e menos intermediada pelas grandes agroindústrias e cooperativas tradicionais (MIOR et al., 2014).

$\mathrm{O}$ que diferencia as cooperativas descentralizadas do modelo tradicional de cooperativa é que, no primeiro, o ativo imobilizado não existe, uma vez que cada sócio é proprietário e responsável pela produção e distribuição, utilizando a cooperativa como amparo jurídico e canal de comercialização (BIALOKORSKI NETO, 2002). Nesse sentido, tem-se a diminuição da intermediação no processo de comercialização, reduzindo custos da transação entre a compra e a venda, além de aproximar o produtor do consumidor, criando uma relação de confiança, uma vez que é possível conhecer a origem da produção. Ainda, sobre o processo de comercialização, sem a intermediação tradicional do atravessador, o consumidor passa a consumir um produto de qualidade, visto sua forma de produção artesanal, com um preço mais justo para ambas as partes (ESTEVAM et al., 2014).

As cooperativas descentralizadas possibilitam ao agricultor familiar diversificar sua produção, não precisando se concentrar em apenas um produto para atender a uma determinada demanda, como acontece na integração com as agroindústrias. Essa flexibilidade produtiva permite aos agricultores escolher o que, como e onde produzir, possibilitando atuarem em novas dinâmicas de mercado. Além disso, os resultados financeiros do processo de produção e comercialização são distribuídos quase em sua totalidade ao cooperado, sendo retido somente um percentual para cobrir os custos operacionais e os determinados pela legislação cooperativa vigente (ESTEVAM et al., 2011).

Por isso essas cooperativas representam uma quebra de paradigma organizacional, social e econômico ao fugirem da ideia majoritária de que, para constituir uma cooperativa, é necessário investir em grandes instalações e em infraestrutura, e, consequentemente, reter em quase sua totalidade as sobras (ESTEVAM et al., 2011). As cooperativas descentralizadas recebem o mesmo tratamento legal das cooperativas tradicionais, tais como: o número mínimo de vinte sócios para a fundação; registro em juntas comerciais; inscrição na receita federal e estadual, bem como todos os demais registros necessários em decorrência do ramo de atividade de cada cooperado.
Essas cooperativas são bem mais flexíveis em comparação às cooperativas tradicionais, por atender às peculiaridades de cada sócio e do mercado. Como se trata de pequenas estruturas organizacionais, a autonomia de cada cooperado é mantida, e o processo de decisão é mais democrático e participativo (ESTEVAM et al., 2014).

Nesse processo, dá-se especial enfoque às cooperativas rurais descentralizadas, o que leva a abordar, no próximo tópico, sobre os espaços de produção e comercialização da agricultura familiar.

\subsection{Espaços atuais de produção e comercia- lização da agricultura familiar}

A organização dos agricultores familiares em cooperativas descentralizadas tem possibilitado a revitalização e diversificação da produção, e, dessa forma, viabilizado a permanência de muitos agricultores no campo. Isso acontece porque o agricultor organizado de forma cooperada tem possibilidade de obter uma renda melhor por meio da valorização e da ressignificação de seus produtos, num trabalho conjunto de valorização do espaço rural (ESTEVAM; MIOR, 2014).

Dessa maneira, tem-se a possibilidade da integração entre produção e consumo, conforme Cruz e Schneider (2010), por meio de cadeias curtas em que há a valorização local de produtos tradicionais com características histórico-culturais, que foram enraizadas socialmente, ressaltando valores tais como: confiança, localidade e reconhecimento entre produtores e consumidores, favorecendo dinâmicas socioeconômicas positivas. Essa estratégia representa a possibilidade de desenvolvimento de algumas regiões, notadamente aquelas que têm procurado inserir-se no mercado por meio da produção e comercialização de alimentos que foram colocados à margem de redes hegemônicas de comercialização. A inserção se dá pela valorização da produção em espaços que a diferenciam dos produtos produzidos, industrialmente e em larga escala, pelo sistema agroalimentar hegemônico, comercializados em mercados alternativos e institucionais.

Quando se refere ao sistema agroalimentar hegemônico, Ploeg (2008) ressalta que o mercado está estruturado e controlado 
pelos impérios alimentares, em que há perda da identidade dos produtos. Sendo assim, o alimento já não é mais produzido num determinado lugar, por determinadas pessoas, num determinado período, nem distribuído por meio de circuitos mais ou menos conhecidos ou, pelo menos, cuja procedência seja conhecida pelos consumidores.

$O$ efeito desse processo é a artificialização da produção, como define Ploeg (2008), caracterizada pelo modo empresarial de fazer agricultura e por um grau elevado de modernização. A partir desse modelo, são criadas novas relações de dependência entre essas instituições, agentes e unidades agrícolas envolvidas. Essas relações de dependência são de natureza dupla: incluem novas relações mercantis, bem como relações técnico-administrativas por meio das quais o processo de trabalho na unidade produtiva é prescrito, condicionado e controlado.

No sistema hegemônico, Giddens (1991) afirma que a confiança das instituições modernas tem suas raízes em sistemas obscuros, nos quais não existe um contato direto entre os atores envolvidos. A essência da confiança se baseia em simbolismos ilusórios sobre a capacidade de um técnico operar sistemas (ou mecanismos) que um leigo não teria capacidade de compreender. Esse fenômeno é caracterizado pelo autor como "confiança sem rosto", pois se acredita na sistematização de um processo justamente pelo fato de a pessoa leiga não compreender o seu funcionamento e não conhecer quem o opera.

Contrapondo-se a esse mercado "sem rosto", surge a abordagem teórica da localização e diversidade dos sistemas agroalimentares. A localidade entra como elemento explicativo principal da diferenciação do desenvolvimento, já que os fenômenos globais sofrem reações, reinterpretações e ressignificações dos sujeitos locais (MIOR et al., 2014). Dessa maneira, propõe-se que as análises sobre mudanças sociais deixem de valorizar apenas as forças externas e passem a ser centradas nos atores sociais locais (PLOEG, 2006). A partir dessa perspectiva teórica, ao tratar das redes sociais colaborativas, estudos (PLOEG, 2006; 2008) fazem uma contraposição entre as perspectivas da globalização e as da relocalização e diversidade dos sistemas alimentares, cujo argumento se centra nos processos de mudança rural, para que, nesse sentido, seja incluída a reestruturação rural a partir de dinâmicas socioeconômicas agrícolas e não agrícolas dos territórios locais e regionais (MIOR et al., 2014).

Portanto, quando se aborda a tipologia dos mercados acessados por agricultores familiares, existe uma carência em termos de literatura que analise as peculiaridades de cada um. Os trabalhos de Abramovay (2003) e Wilkinson (2008) constituem boas referências de ensaios que tentam uma abordagem para compreender as particularidades das diferentes formas de integração mercantil dos agricultores familiares na atualidade.

Na última década, ocorreram profundas transformações nas formas de intermediação entre a produção familiar e o mercado, acesso que agora exige maior autonomia e capacidades próprias por parte dos agricultores. Segundo Wilkinson (2008), ao mesmo tempo, inexiste na literatura um respaldo analítico para pensar os novos espaços da agricultura familiar. Na visão ortodoxa, a pequena produção se caracteriza ou pela falta de acesso a recursos ou pelo uso inadequado destes. Os enfoques, a partir da inovação, valorizam o setor de Pequenas e Médias Empresas (PMEs) apenas na medida em que tratam os novos entrantes abrindo mercados de nicho com base em tecnologias de ponta. O desafio, portanto, é elaborar uma tipologia de mercados que seja relevante para a agricultura familiar e construir uma base analítica que permita compreender a dinâmica desses mercados, que sirva, ao mesmo tempo, para treinar os quadros que trabalham nesse campo (WILKINSON, 2008).

A partir dos anos de 1990, segundo Wilkinson (2008), três enfoques passaram a ser dominantes na discussão sobre agricultura familiar: o primeiro trata da recuperação da noção de agricultura familiar, principalmente na literatura americana e europeia, que substituiu o conceito de pequena produção ou produtor de baixa renda, identificando-o como um sujeito estratégico para o modelo de desenvolvimento desses países; o outro enfoque, também inspirado nas experiências desses países, analisa as atividades não agrícolas como estratégicas para a reprodução social da família rural; o terceiro são estudos que focalizam a dinâmica da integração entre a agricultura familiar e a agroindústria, com 
uma forte tendência de exclusão, com base nas novas exigências de escala e qualidade (ABRAMOVAY, 2003).

Todas essas abordagens mostram fragilidades que apontam para a necessidade de uma nova síntese que já se desenha na convergência em torno da noção de território. Os estudos sobre a agricultura familiar tendem a superestimar o grau de consolidação de certas faixas de produtores por não levarem em conta as fortes transformações na recente dinâmica dos mercados. Em se tratando de mercados para agricultura familiar, quando se abordam essas transformações, especificamente os mercados de produção e comercialização, entende-se que a reprodução social das famílias está diretamente ligada a eles. Com base em Wilkinson (2008), resumidamente, pode-se apontar três tendências ou dinâmicas de mercado, bastante distintas. A primeira é a produção de commodities, como soja, milho, fumo, leite, suínos e aves, que são dominados pelas agroindústrias e atravessadores; a segunda tendência se refere às iniciativas dos agricultores e à construção de sua autonomia contando com a participação de ONGs, como, por exemplo, na produção de orgânicos e na produção de produtos artesanais; a terceira dinâmica está relacionada às políticas públicas (de cunho não assistencialista) que pretendem fortalecer a agricultura familiar criando espaços específicos de comercialização de seus produtos.

Em suma, a partir dos anos noventa, os mercados para os agricultores familiares têm sido favorecidos para atuarem em nichos de mercados em cadeias curtas. Com isso, parte da população tem a possibilidade de acesso a alimentos saudáveis e de qualidade. Dessa forma, no terceiro tópico do artigo, faz-se referência à pesquisa de campo realizada na Região Sul de Santa Catarina.

\section{Espaços de produção e comercialização dos cooperados das cooperativas descentralizadas do sul catarinense}

A pesquisa foi desenvolvida na região sul de Santa Catarina, especificamente nas áreas de abrangência da Associação dos Municípios da Região Carbonífera (AMREC), constituída por 12 municípios associados, a saber: Balneário Rincão, Cocal do Sul,
Criciúma, Forquilhinha, Içara, Lauro Müller, Morro da Fumaça, Nova Veneza, Orleans, Siderópolis, Treviso e Urussanga.

Nesses municípios, a participação da agricultura familiar é de grande relevância, sobretudo em termos sociais e econômicos. Contudo os agricultores enfrentam dificuldades por causa do caráter informal envolvido na comercialização da produção e, consequentemente, vivenciam problemas de acesso a variadas dinâmicas de mercado. Em tal contexto, as cooperativas descentralizadas se apresentam como forma de superar o caráter informal da comercialização da produção, bem como de oportunizar a entrada nos mercados da produção.

Com o objetivo de avaliar os espaços de produção e comercialização dos agricultores familiares em mercados alternativos e institucionais, buscou-se obter informações junto aos cooperados de algumas das cooperativas descentralizadas da região em estudo. Ao todo foram entrevistados 18 agricultores familiares de seis cooperativas oriundas de seis municípios do sul catarinense, conforme descrição que segue: Cooperativa de Produção Agroindustrial dos Agricultores Familiares de Içara-SC (Coopafi); Cooperativa de Produção Agroindustrial dos Agricultores Familiares de Forquilhinha-SC (Coonafor); Cooperativa Nosso Fruto de Criciúma-SC; Cooperativa de Produção Agroindustrial dos Agricultores Familiares Fumacences (Cooaff); Cooperativa de Produção Agroindustrial dos Agricultores Familiares de Urussanga-SC (Coofasul); Cooperativa dos agricultores familiares de Nova Veneza-SC (Coofanove).

\subsection{Perfil sociodemográfico dos entrevistados}

A tabela 1 apresenta o perfil sociodemográfico dos entrevistados. Com o objetivo de manter o anonimato dos entrevistados, a identificação foi feita por meio de numeração, em ordem decrescente por idade. Dos 18 entrevistados, quatro são do sexo feminino e 14 do sexo masculino, com idades entre 24 e 62 anos. A grande maioria é casada, com exceção de duas mulheres solteiras e um homem viúvo. Outro ponto a ser destacado se refere à média de idade dos entrevistados, superior a cinquenta anos, o que acompanha a tendência de envelhecimento da população rural. 
Tabela 1 - Perfil sociodemográfico dos entrevistados

\begin{tabular}{ccccccc}
\hline Entrevistado & Sexo & Idade & $\begin{array}{c}\text { Estado } \\
\text { Civil }\end{array}$ & $\begin{array}{c}\text { Número de } \\
\text { Filhos }\end{array}$ & $\begin{array}{c}\text { Filhos na } \\
\text { propriedade }\end{array}$ & $\begin{array}{c}\text { Tempo de } \\
\text { Associado }\end{array}$ \\
\hline 1 & Feminino & 24 & Casada & 0 & 0 & 4 meses \\
2 & Feminino & 31 & Solteira & 0 & 0 & 1 ano \\
3 & Masculino & 38 & Viúvo & 2 & 0 & 1 ano \\
4 & Masculino & 41 & Casado & 3 & 1 & 3 anos \\
5 & Masculino & 45 & Casado & 1 & 1 & 10 anos \\
6 & Masculino & 47 & Casado & 3 & 0 & 3 anos \\
7 & Masculino & 47 & Casado & 2 & 0 & 5 anos \\
8 & Masculino & 47 & Casado & 3 & 0 & 3 anos \\
9 & Masculino & 49 & Casado & 2 & 2 & 3 anos \\
10 & Masculino & 50 & Casado & 2 & 0 & 3 anos \\
11 & Masculino & 50 & Casado & 3 & 1 & 3 anos \\
12 & Masculino & 50 & Casado & 2 & 0 & 4 anos \\
13 & Masculino & 53 & Casado & 4 & 0 & 9 anos \\
14 & Masculino & 54 & Casado & 2 & 0 & 5 anos \\
15 & Masculino & 57 & Casado & 2 & 0 & 5 anos \\
16 & Feminino & 57 & Casada & 1 & 0 & 5 anos \\
17 & Masculino & 58 & Casado & 3 & 0 & 5 anos \\
18 & Feminino & 62 & Solteira & 0 & 0 & 5 anos \\
\hline Peno
\end{tabular}

Fonte: Pesquisa de campo (2014).

A pesquisa evidenciou algumas barreiras para a viabilidade da comercialização dos produtos provenientes da agricultura familiar, entre as quais a inspeção sanitária e questões tributárias. Estevam et al. (2012) já haviam observado essas dificuldades e afirmam que os pequenos produtores rurais encontram barreiras para entrar no mercado em função da vigilância sanitária e tributária, principalmente quando a venda ultrapassa o espaço territorial municipal. Para comercializar fora do município, como os estabelecimentos rurais têm licenciamento para comercializar a produção dentro do município, pelo Sistema de Inspeção Municipal (SIM), alguns cooperados optam por se associar em mais de uma cooperativa para ampliar os espaços de comercialização. Essa é uma estratégia que muitos cooperados têm adotado.

Em relação ao número de filhos, totalizam-se 35 descendentes. Destes, apenas cinco permaneceram na propriedade rural e 30 migraram para os centros urbanos dos municípios da região. Gaviria e Menasche (2006) explicam a migração dos jovens do campo para das cidades, justificando que os pais incentivam os filhos a estudarem para sair do trabalho rural. Quando estes atingem a idade adulta, buscam a independência familiar e a garantia de um salário mensal.

\subsection{A divisão do trabalho nos estabeleci- mentos}

Dos 18 agricultores entrevistados, apenas dois não possuem áreas de produção e moradia próprias. Os demais entrevistados possuem pequenas propriedades que variam de tamanho entre 2,5 a 22 hectares. Os agricultores produzem e comercializam uma grande diversidade de produtos. Entretanto o milho e o arroz ainda são mais produzidos, seguidos do leite, com um total de quatro estabelecimentos. Os embutidos de carne suína e o fumo também estão entre os mais produzidos, com três estabelecimentos. Os demais produtos variam entre dois e três estabelecimentos. É importante destacar que, entre todos os entrevistados, nenhum pratica a monocultura, ou seja, os estabelecimentos produzem mais de um tipo de alimento para o consumo e para o mercado.

Conforme se verifica, os agricultores têm buscado a diversificação da produção como forma alternativa de obtenção de renda e, como afirma Bianchini (2007), também produzem para o autoconsumo, uma vez que o produtor que cultiva uma única cultura corre o risco de passar períodos do ano sem renda em função da sazonalidade do produto. De acordo com Schejtman e Berdegué (2004), 
o desenvolvimento da agricultura familiar depende do fortalecimento de pequenos empreendedores rurais pela diversificação da produção e da endogenia, pelas cadeias de cooperação de populações que vivem em estado de pobreza e ampliação do seu poder competitivo. Outra característica da agricultura familiar é a família como centro produtivo e, ainda, a propriedade agrícola tem como sustentação a tríade família-produção-trabalho (WANDERLEY, 2009).

Como a força de trabalho é tipicamente familiar, buscou-se compreender como os entrevistados se organizam para a divisão do trabalho dentro da propriedade. Os entrevistados 05, 06 e 10 têm seus filhos trabalhando na propriedade, porém as divisões de tarefas não são claras: todos os membros da família desempenham todas as funções. Os entrevistados $09,11,15,16$ e 17 contam com a força de trabalho somente do casal, o esposo e a esposa executam todas as atividades. O entrevistado 01 tem um empreendimento que conta com a mão de obra de cinco funcionários, mesmo assim, a divisão de tarefas não é clara, cada funcionário desempenha a atividade de acordo com a demanda. $O$ entrevistado 18 conta com a ajuda de seu irmão, de sua cunhada e de seu sobrinho para realizar as tarefas, mas também não tem uma divisão clara das funções a serem desempenhadas.

Dos 18 entrevistados, quatro deles relataram uma divisão clara de trabalho na propriedade e unidade de produção. Cabe destacar o entrevistado 02 , cuja divisão de trabalho fica disposta da seguinte maneira: uma filha e a esposa ficam encarregadas pela produção; o esposo embala e faz as entregas; a outra filha é responsável pelas vendas. Além deste, o entrevistado 14 é responsável pela produção de arroz, e a esposa pelos embutidos de carne suína.

Como se verifica, a divisão do trabalho nos estabelecimentos não é bem definida. Isso pode ser explicado porque não há separação entre a produção para o mercado e para o autoconsumo, diferentemente da divisão tradicional da agricultura em que se tinha a separação entre a produção para o autoconsumo produzido majoritariamente pelas mulheres e para o mercado produzido pelos homens.
3.3 Funções nas cooperativas e espaços de produção e comercialização dos cooperados

Em relação ao desempenho de funções nas cooperativas, do total de 18 entrevistados, oito ocupam algum cargo na diretoria. Em termos de relacionamento entre os cooperados, 11 entrevistados não percebem conflitos de interesses nas cooperativas; sete entrevistados destacaram a existência de divergências dentro das cooperativas, como o individualismo, a concorrência entre cooperados, questões de percentual retido e o preço pago pelos produtos do Programa de Aquisição de Alimentos (PAA).

Entretanto todos concordam que, depois que se tornaram cooperados, foi possível aumentar a produção e o retorno financeiro. É importante destacar o caso dos entrevistados 03 e 06, que eram produtores de fumo e, como cooperados, passaram a cultivar mais de um tipo de alimento, recebendo o mesmo retorno financeiro em função da capacidade que a marca da cooperativa tem de agregar valor aos produtos. É o que relata o entrevistado 15:

Depois de entrar na cooperativa, nós conseguimos tirar um dinheiro maior dos produtos que a gente vende, porque aquela marquinha que vai no pacote [dos produtos] já mostra que o que a gente produz tem qualidade e tem o certificado da inspeção.

Além da valorização dos produtos, os entrevistados destacaram que a entrada na cooperativa promoveu aumentos significativos nas vendas dos produtos. Quatro entrevistados declararam, ainda, que a cooperativa possibilitou a diversificação da produção, visto que abriu espaços no mercado para várias culturas. Os entrevistados 05, 10 e 13 observaram que a cooperativa auxiliou na revitalização da produção de defumados, hortaliças e feijão.

A comercialização da produção ocorre, principalmente, nas feiras municipais, onde todos os entrevistados participam semanalmente. A venda de porta em porta também é um canal importante de comercialização e bastante utilizado pelos agricultores, e, para 08 entrevistados, um dos principais meios de comercialização da produção. Outro mercado importante são os programas governamentais, tais como Programa Nacional de Alimentação Escolar (PNAE), Programa de Aquisição de 
Alimentos (PAA) e a Companhia Nacional de Abastecimento (CONAB), acessados por 12 dos dezoito entrevistados.

Entretanto cabe ressaltar as feiras livres municipais como um dos principais canais de comercialização utilizado por esses agricultores. O estudo de Estevam, Salvaro e Lanzarini (2014) aponta a importância das feiras para comercialização da produção dos cooperados, bem como o seu ressurgimento na última década, as quais praticamente haviam desaparecido na região e, atualmente, estão ressurgindo e até mesmo sendo criadas outras em locais que não existiam. Esse fato está relacionado também à formação de cooperativas, que se organizaram na perspectiva de comercialização de seus produtos na venda direta ao consumidor e, assim, consolidando uma maneira diferenciada de entrada no mercado. A comercialização da produção em feiras pode ser vista como um fator positivo, pois, ao possibilitar o contato direto dos produtores com os consumidores, permite conhecer preferências, criar vínculos de amizade e respeito que vão além do ato de vender alimentos. Ou seja, possibilitam a criação de laços de confiança, amizade, reciprocidade e credibilidade.

\subsection{A qualidade dos alimentos na perspectiva dos entrevistados}

No processo de consumo alimentar moderno, a confiança tem sido um preceito que não se limita à relação de parentesco ou amizade entre produtor e consumidor. Alves $(2005$, p. 87) caracteriza a confiança como “[...] um bem intangível signatário dos sistemas peritos", ou seja, as pessoas não têm contato com o agricultor que plantou os alimentos que elas consomem, nem com o cozinheiro que os cozinhou e muito menos com o processo produtivo das grandes cadeias agroalimentares, ou com os órgãos responsáveis pela fiscalização sanitária. $\mathrm{Na}$ atualidade, as pessoas são, na maioria das vezes, dependentes da garantia de confiança de uma grande empresa.

As cadeias produtivas curtas vêm justamente na contramão desse paradigma, visto que seu objetivo é criar relações diretas entre consumidor e produtor, resgatando conceitos pré-modernos de confiança que, de acordo com Giddens (1991), ocorriam pelos contatos face a face, ligações de parentesco, amizade, comunidade local, tradições e práticas religiosas. Certa relação de confiança entre produtor e consumidor pode ser observada no relato do entrevistado 17:

Os produtos familiares têm mais qualidade, porque quando vem alguém pra comprar, eles veem quem que está vendendo e sempre acaba se conhecendo. [...] Eles sabem como que a gente planta, a terra que nós preparamos, e daí então eles gostam e sabem que o produto é de qualidade.

De modo geral, os agricultores familiares entrevistados atribuem qualidade aos seus produtos e a justificam a partir de alguns fatores: baixo ou não uso de agrotóxicos; compra direta que permite o conhecimento da origem do produto; produtos frescos, produzidos e comercializados na mesma semana; e, ainda, o cuidado com a produção.

\begin{abstract}
Aqui a gente produz com carinho. Nós cuidamos de cada produto e produzimos especial para cada cliente. Nós colocamos pouco agrotóxico, o produto é praticamente orgânico. Daí dá pra dizer que tem qualidade, porque aqueles produtos lá do mercado tem tudo os conservantes, os agrotóxico e tudo isso. Porque só assim pra uma laranja ficar bonita por uma semana e pro leite aguentar mais de 15 dias fora da geladeira. (Entrevistado 12).

Percebe-se que o agricultor, com todo o seu conhecimento pragmático sobre os alimentos e suas formas de produção, reconhece a importância de se produzir um produto de qualidade, além de se fazer questionamentos quanto à qualidade dos produtos industria-
\end{abstract} lizados.

\section{Considerações finais}

A partir da década de 1980, por um lado, teve-se o aumento do controle do mercado pelos impérios alimentares, que atuavam em cadeias longas, o que possibilitou a perda da identidade dos produtos, com restrição à entrada para os agricultores familiares; por outro, os agricultores foram favorecidos para atuarem em nichos de mercados em cadeias curtas. Com isso, parte da população passou a ter a possibilidade de acesso a alimentos saudáveis e de qualidade nessa cadeia curta.

Nesse contexto, na região estudada, as cooperativas descentralizadas têm viabilizado a entrada autônoma dos agricultores familiares 
no mercado. Esse acesso se dá de forma direta e sem a intermediação de atravessadores. Esse contato "face a face" reduz os custos de transição ao aproximar o produtor do consumidor, uma vez que é possível conhecer a origem dos produtos.

Em relação aos entrevistados, todos afirmaram que, depois de se tornarem cooperados, houve aumento na quantidade produzida e na comercialização de seus produtos. Além disso, passaram a produzir mais de um tipo de produto, havendo o aumento da renda na propriedade em função da possibilidade de se ter uma marca própria da cooperativa, o que contribui para agregar valor aos produtos.

Pelos resultados obtidos, pôde-se constatar que as vendas têm acontecido nas duas dinâmicas: no mercado alternativo (participação em feiras) e na venda em domicílio; também que o Institucional tem se mostrado de grande importância na composição da renda das famílias.

\section{Referências}

ABRAMOVAY, Ricardo. Desenvolver os territórios fortalecendo o empreendedorismo de pequeno porte. In: FÓRUM INTERNACIONAL TERRITÓRIO, DESENVOLVIMENTO RURAL E DEMOCRACIA, 1., 2003, Fortaleza. Relatório Final. Disponível em: <http://www.fea.usp.br/feaecon//media/fck/File/ empreendedorismo_e_desenvolvimento_territorial. pdf>. Acesso em: 23 fev. 2013.

ALVES, A. F. Boca invisível - incerteza, risco e confiança na rede de produção e consumo. In: CASARIL, Karley Braga Pereira Bento; PLEIN, Clério. Segurança alimentar numa perspectiva multidisciplinar: contribuição ao debate brasileiro. Francisco Beltrão: Unioeste, 2005, p. 79-90.

BIALOSKORSKI NETO, Sigismundo. Estratégias e cooperativas agropecuárias: um estudo analítico. In: SEMINÁRIO DE POLÍTICA ECONÔMICA E AGRONEGÓCIOS, 2002, Viçosa, MG, Anais... Viçosa: UFV, out. 2002. Disponível em: <http://www.fearp. usp.br/ sigbial/inserir_out2002/Estrategias_e_Cooperativas_Sig2.pdf>. Acesso em: 14 jun. 2014.

BIANCHINI, Valter. O universo da agricultura familiar e sua contribuição ao desenvolvimento rural. Brasília: Embrapa, 2007. Disponível em: <http:/ / redeagroecologia.cnptia. embrapa.br/biblioteca/agricultura-familiar $>$. Acesso em: 02 mar. 2014.

DENARDI, Reni Antônio. Agricultura familiar e políticas públicas: alguns dilemas e desafios para o desenvolvimento rural sustentável. Rev. Agroecologia e Desenvolvimento Rural Sustentável, Porto Alegre, v. 2, n. 3, p. 56-62, 2001. Disponível em: <http:/ / www2.ufersa.edu. br/portal/view/uploads/setores/241/_Agricultura. pdf>. Acesso em: 10 fev. 2014.
CRUZ, F.; SCHNEIDER, Sérgio. Qualidade dos alimentos, escalas de produção e valorização de produtos tradicionais. Rev. Bras. de Agroecologia, v. 5, n. 2, p. 22-38, 2010. Disponível em: <http://www.ufrgs.br/pgdr/ arquivos/778.pdf>. Acesso em: 13 jun. 2012.

ESTEVAM, Dimas de O. et al. Cooperativas descentralizadas: (re)conectando pessoas, produtos e o lugar em cadeias curtas de produção e comercialização. In: ESTEVAM, Dimas de Oliveira; MIOR, Luiz Carlos (Org.). Inovações na agricultura familiar: as cooperativas descentralizadas em Santa Catarina. Florianópolis: Insular, 2014.

ESTEVAM, Dimas de O.; SALVARO, Giovana Ilka Jacinto; LANZARINI, Joelcy José Sá. O perfil socioeconômico dos/as consumidores/as das feiras livres municipais da agricultura familiar na região sul catarinense. In: SIMPÓSIO SOBRE REFORMA AGRÁRIA E QUESTÕES RURAIS, 6., 2014, Araraquara. Anais... Araraquara: UNIARA, 28-31 maio 2014. CD-ROM.

ESTEVAM, Dimas de O.; MIOR, Luiz Carlos. (Org.). Inovações na agricultura familiar: as cooperativas descentralizadas em Santa Catarina. Florianópolis: Insular, 2014.

ESTEVAM, Dimas de O. et al. Cooperativas rurais nãopatrimoniais (ou virtuais) e o difícil caminho da formalidade: o caso dos agricultores familiares da região do sul do Estado de Santa Catarina. REDD - Revista Espaço de Diálogo e Desconexão, Araraquara, v. 5, n. 2, jul./dez. 2012.

ESTEVAM, Dimas de O. et al. Cooperativismo virtual: o caso da cooperativa de produção agroindustrial familiar de Nova Veneza (COOFANOVE), em Santa Catarina. Cadernos de Ciência E Tecnologia, Brasília, v. 28, n. 2, p. 485-507, maio/ago. 2011.

GAVIRIA, Margarida Rosa; MENASCHE, Renata. A juventude rural no desenvolvimento territorial: análise da posição e do papel dos jovens no processo de transformação do campo. Rev. Estudo e Debate, Rio Grande do Sul, v. 10, n. 1, p. 69-82, 2006. Disponível em: <http://www.ufrgs. br/pgdr/arquivos/526.pdf>. Acesso em: 25 maio 2014.

GIDDENS, Anthony. As consequências da modernidade. São Paulo: UNESP, 1991.

GIL, Antonio Carlos. Métodos e técnicas de pesquisa social. São Paulo: Atlas, 2010.

GOODMAN, David; SORJ, Bernardo; WILKINSON, John. Da lavoura às novas biotecnologias: agricultura e indústria no sistema internacional. Rio de Janeiro: Campus, 1990.

MIOR, L. C. et al. Inovações organizacionais da agricultura familiar: as agroindústrias e cooperativas descentralizadas no sul catarinense. In: CONGRESSO SOBER - SOCIEDADE BRASILEIRA DE ECONOMIA, ADMINISTRAÇÃO E SOCIOLOGIA RURAL, 52., 2014, Goiânia. Anais... Goiânia, GO: SOBER, 2014. p.1-20. Disponível em: <http:/ /icongresso.itarget.com.br/tra/ arquivos/ser.4/1/3664.pdf>. Acesso em: 14 jun. 2015.

MOREIRA, Roberto José. Agricultura familiar: processos sociais e competitividade. Rio de Janeiro: Mauad, 1999.

PALMEIRA, Moacir. Modernização, Estado e questão agrária. Estudos Avançados, São Paulo, v. 3, n. 7, p. 87-108, 1989. Disponível em: <http://www.scielo. br/scielo.php?script=sci_arttext\&pid=S0103-401419 89000300006\&lng=en\&nrm=iso >. Acesso em: 10 jun. 2014. 
PLOEG, Jan Douwe van der. Camponeses e impérios alimentares: lutas por autonomia e sustentabilidade na Era da Globalização. Porto Alegre: Editora da UFRGS, 2008.

O modo de produção camponês revisitado. In. SCHNEIDER, Sérgio. A diversidade da agricultura familiar. Porto Alegre: Editora da UFRGS, 2006.

RICHARDSON, Roberto Jerry. Pesquisa social: métodos e técnicas. 3. ed. São Paulo: Atlas, 1999.

SCHEJTMAN, Alexander; BERDEGUÉ, Julio A. Desarrollo territorial rural. Santiago: Rimisp - Centro Latinoamericano para el Desarrollo Rural, 2004. Disponível em: <http://www.rimisp.org/wp-content/ files_mf/1363093392schejtman_y_berdegue2004_desarrollo_territorial_rural_5_rimisp_CArdumen.pdf $>$. Acesso em: 04 mar. 2014.
SCHNEIDER, Sérgio. Prefácio. In: CONTERATO, Marcelo Antônio et al. (Org.). Mercados e agricultura familiar: interfaces, conexões e conflitos. Porto Alegre: Via Sapiens, 2013, p. 08-11. Disponível em: <http:// www.ufrgs.br/pgdr/livros/outras_publicacoes/ ebooks/03_ebook_PGDR.pdf>. Acesso em: 20 jun. 2014.

WANDERLEY, Maria de Nazareth Braudel. Raízes históricas do campesinato brasileiro. In:__. Mundo rural como um espaço de vida. Porto Alegre: Editora da UFRGS, 2009, p. 155-183.

WILKINSON, John. Mercados, redes e valores: o novo mundo da agricultura familiar. Porto Alegre: Editora da UFRGS, 2008. 